\title{
Early adulthood television viewing and cardiometabolic risk profiles in early middle age: results from a population, prospective cohort study
}

\author{
E. Stamatakis • M. Hamer • G. D. Mishra
}

Received: 15 July 2011 /Accepted: 30 September 2011 /Published online: 6 November 2011

(C) Springer-Verlag 2011

\begin{abstract}
Aims/hypothesis Little research has been done on the longterm longitudinal associations between markers of sedentary behaviour and health risks. We hypothesised that television (TV) viewing in early to mid-adulthood predicts an adverse cardiometabolic risk factor profile in middle age independently of participation in physical activity.

Methods We used prospective data from 5,972 (2,947 men) participants of the 1958 British Birth Cohort study. TV viewing and exercise frequency were obtained at age 23 years. Daily TV viewing and weekly moderate to vigorous physical activity were assessed at age 44 years, as well as $\mathrm{HbA}_{1 \mathrm{c}}$, triacylglycerol, total and HDL-cholesterol, systolic and diastolic blood pressure, and waist circumference. We used generalised linear models and multiple linear regression to examine the associations between TV viewing at age 23 years and the cardiometabolic risk markers (including a clustered cardiometabolic risk score) at 44 years, while adjusting for sex, exercise participation and TV viewing at age 44 years, and other potential confounders.

Results In the multivariable models, TV viewing frequency at age 23 years showed positive associations with
\end{abstract}

Electronic supplementary material The online version of this article (doi:10.1007/s00125-011-2358-3) contains peer-reviewed but unedited supplementary material, which is available to authorised users.

E. Stamatakis $(\bowtie) \cdot$ M. Hamer $\cdot$ G. D. Mishra

Department of Epidemiology and Public Health,

University College London,

1-19 Torrington Place,

London WC1E 6BT, UK

e-mail: e.stamatakis@ucl.ac.uk

E. Stamatakis $\cdot$ M. Hamer

Physical Activity Research Group (PARG),

Population Health Domain, University College London,

London WC1E 6BT, UK
C-reactive protein (generalised linear model change $12.6 \%, 95 \%$ CI 3.5, 22.8; $p=0.005$ ), fibrinogen (change $1.8 \%, 95 \%$ CI $0.3,3.3 ; p=0.020)$, waist circumference (coefficient 1.17, 95\% CI 0.32, 2.01; $p=0.004$ ), systolic (coefficient 1.44, 95\% CI $0.33,2.54 ; p=0.019$ ) and diastolic (coefficient $0.75,95 \% \mathrm{CI}-0.01,1.51 ; p=0.053$ ) blood pressure, and clustered cardiometabolic risk score (men only, coefficient $0.06,95 \%$ CI $0.01,0.11 ; p=0.038$ ). Adjustments for baseline (age 23 years) BMI attenuated these associations towards null.

Conclusions/interpretation TV viewing habits in early adulthood are associated with adverse cardiometabolic profiles in early middle adulthood that are independent of TV viewing habits and physical activity in middle age, but not independent of BMI in early adulthood.

Keywords British birth cohort - Cardiovascular risk factors $\cdot$ Longitudinal $\cdot$ Metabolic $\cdot$ National Child Development Study $\cdot$ Physical activity $\cdot$ Primary prevention $\cdot$ Sedentary behaviour/behaviour $\cdot$ Television
Abbreviations
BBC58 1958 British birth cohort
CRP C-reactive protein
CVD Cardiovascular disease
MVPA Moderate to vigorous physical activity
TV Television

\section{Introduction}

The protective effects of regular moderate to vigorous physical activity (MVPA) on health are well established [1]. Emerging evidence consistently suggests that sedentary behaviour (prolonged sitting) is linked to several cardio- 
metabolic conditions, including obesity [2], dyslipidaemia [3] and raised plasma glucose levels [4-6], independently of participation in MVPA. With the exception of a few studies $[7,8]$, most of the evidence in this area is cross-sectional. The role of adiposity in explaining the associations between sedentary behaviour and cardiometabolic risk is inconclusive: there are indications that body weight status can predict sedentary behaviour, but sedentary behaviour may not predict future obesity [10]. Most studies that have examined the associations between indicators of sedentary behaviour and clustered risk (such as the metabolic syndrome) were cross-sectional or had small sample sizes [5, 11, 12]. One of the few longitudinal studies in this field [13] found associations between increase in television (TV) viewing over time and adverse changes in clustered cardiometabolic risk score, although baseline TV viewing was not associated with any of these outcomes or with raised triacylglycerol, HDL-cholesterol and plasma glucose. The association between glycaemic status indices such as plasma glucose or $\mathrm{HbA}_{1 \mathrm{c}}$ and indicators of sedentary behaviour merit further attention because the existing evidence is particularly inconsistent, with some studies showing an association [4, 5], whereas others do not $[6,13]$ (E. Stamatakis, M. Hamer, K. Tilling and D.A. Lawlor, unpublished results). Besides these glycaemic status indices, recent work of ours [8] suggests that low-grade inflammation explains a substantial proportion $(\sim 20 \%)$ of the association between screen-based leisure and cardiovascular events. Another recent study [14] reported links between sedentary behaviour and pulmonary embolism in women, suggesting that sittingrelated activities may cause or exacerbate venous stasis, increasing thrombotic tendencies and plasma viscosity [15]. Nevertheless, no study has looked at the longitudinal associations between indices of sedentary behaviour and inflammatory (such as C-reactive protein [CRP]) or haemostatic (such as fibrinogen) markers.

Television viewing is the most important indicator of non-occupational sitting behaviour [16]. Recent timeuse surveys [17-19] indicate that, aside from sleeping, watching TV is the behaviour that occupies the most time in the domestic setting. For example, adults living in England spend over $3 \mathrm{~h}$ a day on average watching TV [20]. The deleterious associations between TV viewing and both cardiometabolic disease risk and mortality have been highlighted in a recent meta-analysis [21]. If overall sitting or its constituent components (e.g. TV viewing) are established to be independent predictors of risk, clinical and public health recommendations [22-24] should explicitly address these behaviours, in addition to recommending MVPA. Moreover, as only a minority of adults in Western populations participate regularly in sport and exercise activities [25] and those who do not are more likely to develop cardiovascular disease (CVD) or die prematurely, it may be possible to reduce the risk of non-participators by restricting sitting time and increasing non-exercise activity (e.g. standing and ambulating) throughout the day [26]. There is no conclusive evidence comparing the feasibility or long-term effectiveness of interventions designed to increase formal exercise versus decreasing sitting behaviour during the day. However, the latter approach may be more promising in terms of long-term adherence, as it would involve more subtle lifestyle changes and fewer of the commonly cited barriers [27] for joining a sporting or lifestyle exercise programme. Furthermore, if early adulthood sedentary behaviour habits are shown to be associated with adverse cardiometabolic risk profiles in middle age, preventive behavioural interventions may need to target younger populations that typically do not have raised risk factors and have a relatively low risk of CVD, and are therefore rarely targeted by interventions.

The aim of this study was to examine the longitudinal associations between a key indicator of sedentary behaviour (TV viewing) in early adulthood and comprehensive cardiometabolic risk profiles in early middle age. A secondary aim was to test whether any observed associations are independent of baseline BMI.

\section{Methods}

Sample The 1958 British Birth Cohort (BBC58) includes all children born in Great Britain (England, Scotland, Wales) in 1 week of March $1958(n=17,638)$ [28]. Follow-up data were collected when participants were aged 23 years. In 2002 and 2003 (age 44 years), 12,069 participants (68\% of original sample) were invited to a household-based clinical examination, of whom 9,377 responded positively and completed the examination. BBC58 complies with the Declaration of Helsinki, participants provided informed consent, and approval for the 2002 and 2003 data collection was obtained from the South-East Multi-centre Research Ethics Committee, UK.

Outcome measures at age 44 years Non-fasting blood samples were collected by trained nurses and mailed to collaborating laboratories. All assays had coefficients of variation of $<10 \%$. The blood samples analysis methods and outcomes of the quality control procedures have been described in detail elsewhere [29]. The blood analytes considered were: $\mathrm{HbA}_{1 \mathrm{c}}$, triacylglycerol, total cholesterol, HDL-cholesterol, fibrinogen and CRP. Although information on BMI at age 44 years was available, we chose waist circumference as the adiposity marker outcome, because we 
have shown that it is better than BMI for prediction of cardiovascular risk [30]. Waist circumference was measured to the nearest millimetre and was defined as the midpoint between the lower ribs and iliac crest in the mid-axillary line. Systolic and diastolic blood pressure and resting pulse rate were measured using a monitor (Omron 907; Omron Healthcare UK, Milton Keynes, UK).

Exposure measures at age 23 years TV viewing was assessed by an interview-administered questionnaire and reported as weekly frequency $(\geq 5,3-4,1-2$ times per week, 2-3 times in last 4 weeks, once in last 4 weeks, not at all in last 4 weeks). For the analyses presented here, TV viewing at 23 years was quantified as $\geq 5,3-4$ and $\leq 2$ times per week, a categorisation used in a previous publication [31].

Covariables and contextual variables Average daily TV viewing was assessed by self-completion questionnaire at age 44 years $(3-4,2-3,1-2,<1 \mathrm{~h} /$ day or none). Similarly to TV viewing, physical activity had been assessed by interviews at age 23 years and was assessed by a self-completed questionnaire at age 44 years. At 23 years, questions enquired about frequency of sports and exercise participation ( $\geq 5,3-4,1-2$ times per week, 2-3 times per month, once per month, none). At 23 years, self-reports of weight and height were obtained to calculate BMI. Physical activity at age 44 years was assessed using EPAQ2, a previously validated self-completion questionnaire, including work, home and leisure-time activity during the past year $[32,33]$. Using established physical activity intensity charts [34] and a previously described intensity classification method [35], we calculated MVPA in min/week and the percentage of participants meeting the current MVPA recommendations ( $\geq 150 \mathrm{~min} / \mathrm{week}$ ) [23]. Information on medication, smoking and alcohol habits at age 44 years was collected by interviewers. Socioeconomic position at age 44 years was calculated using the Registrar General's classification, a UK-specific index that is based on occupation [36].

Data handling and statistical analysis As previously [8], CRP, triacylglycerol and fibrinogen were log-transformed to improve the normality of distribution. We calculated the ratio of total to HDL-cholesterol, as this has been shown to be the most informative cholesterol-related index $(40 \%$ more informative than non-HDL-cholesterol and more than twice as informative as total cholesterol) [37]. We used existing methods $[13,38]$ to develop a continuous clustered cardiometabolic risk score on the basis of the examined outcomes $\left(\mathrm{HbA}_{1 \mathrm{c}}\right.$, triacylglycerol, total cholesterol, HDLcholesterol, fibrinogen, CRP, blood pressure, waist circumference). After $\log$ transformation and $z$ score conversion $(z=[$ value - mean $] / \mathrm{SD})$ of all cardiometabolic variables (average blood pressure was used as an index for systolic and diastolic blood pressure), the $z$ scores were summed and the sum was divided by 8 to compile the cardiometabolic risk score with units of SD. For HDL-cholesterol (which is protective for cardiometabolic risk), the $z$ score was multiplied by -1 . Univariate associations between the TV viewing variables and the covariates and outcomes were assessed using $\chi^{2}$ (categorical variables) or KruskalWallis one-way ANOVA (continuous variables).

The association between TV viewing frequency at age 23 years and each cardiometabolic outcome or the clustered score was examined using generalised linear models and multiple linear regression. Different models were adjusted for: (1) sex; (2) additionally for smoking, alcohol, CVD medication and social class at age 44 years; and (3) additionally for exercise at age 23 years, and MVPA and TV viewing times at age 44 years. Generalised linear model coefficients indicate mean differences (in values for each risk factor) between the reference category (two or fewer times a week) and each of the other TV viewing groups at age 23 years. We tested for sex interactions in terms of each cardiometabolic risk marker and clustered cardiometabolic risk score by entering an interaction term in a basic generalised linear model with each risk indicator as the outcome. As we found little appreciable evidence of such interactions, all analyses were sex-adjusted but not sex-stratified. We evaluated the role of baseline body weight status by running additional multivariable generalised linear models that were also adjusted for BMI at age 23 years.

\section{Results}

Of the 9,377 respondents contacted during the 2002 and 2003 data collection, 5,972 (2,947 men) had valid information for all required variables. Excluded respondents were more likely to be men, current smokers, rare or never alcohol drinkers, on CVD medication, from a manual work social class and inactive at age 44 years, and also more likely to report more than $4 \mathrm{~h} /$ day of TV viewing at age 44 years (Electronic supplementary material [ESM] Table 1). The characteristics of those included in the analysis sample are presented in Table 1. Participants reporting a higher TV viewing frequency at age 23 years had higher levels of smoking, $\mathrm{HbA}_{1 \mathrm{c}}$, triacylglycerol, fibrinogen, CRP, waist circumference, systolic and diastolic blood pressure, and clustered cardiometabolic risk. They were also less likely to be men and to belong to a non-manual work social class, and had lower levels of alcohol consumption, physical activity at ages 23 and 44 years, and HDL- 
Table 1 Sample characteristics and biological risk factor distribution by TV viewing frequency at age 23 years: the BBC58 $(n=5972)$
Unless otherwise indicated, values are in mean (SD); due to differences in measurement scales, mean values $<10$ are shown with two decimal points, 10-99 with one decimal point and $\geq 100$ with no decimal point ${ }^{\mathrm{a}} \mathrm{BMI} \geq 25 \mathrm{~kg} / \mathrm{m}^{2}$; ${ }^{\mathrm{b}}$ participating in sports at least once a week; ${ }^{\mathrm{c}}$ defined as meeting the physical activity guidelines through recreational MVPA $(\geq 150$ $\mathrm{min} /$ week); ${ }^{\mathrm{d}}$ calculated as total cholesterol: HDL-cholesterol

\begin{tabular}{|c|c|c|c|c|}
\hline \multirow{2}{*}{$\begin{array}{l}\text { Variable } \\
\text { Characteristic }\end{array}$} & \multicolumn{3}{|c|}{ TV frequency at age 23 years (times per week) } & \multirow[t]{2}{*}{$p$ value } \\
\hline & $\leq 2$ & $3-4$ & $\geq 5$ & \\
\hline$n$ & 914 & 1033 & 4025 & \\
\hline Male sex $(\%)$ & 51.3 & 52.9 & 48.0 & 0.009 \\
\hline Manual work social class $(\%)$ & 25.0 & 28.6 & 38.4 & $<0.001$ \\
\hline Never smoked (\%) & 53.1 & 51.2 & 43.8 & $<0.001$ \\
\hline Alcohol $\geq 4$ times/week $(\%)$ & 30.3 & 28.7 & 24.6 & $<0.001$ \\
\hline CVD medication at age 44 years (\%) & 7.11 & 6.49 & 8.12 & 0.136 \\
\hline Overweight or obese at age 23 years $(\%)^{\mathrm{a}}$ & 9.79 & 11.6 & 16.4 & $<0.001$ \\
\hline Exercise at age 23 years $(\%)^{b}$ & 43.5 & 38.5 & 30.4 & $<0.001$ \\
\hline Active at age 44 years ${ }^{c}(\%)$ & 61.5 & 59.0 & 51.7 & $<0.001$ \\
\hline \multicolumn{5}{|l|}{ Risk factor } \\
\hline $\mathrm{HbA}_{1 \mathrm{c}}(\%)$ & $5.20(0.66)$ & $5.21(0.57)$ & $5.26(0.68)$ & 0.012 \\
\hline $\mathrm{HbA}_{1 \mathrm{c}}(\mathrm{mmol} / \mathrm{mol})$ & $33.3(7.20)$ & $33.4(6.20)$ & $34.0(7.40)$ & \\
\hline Triacylglycerol (mmol/l) & $1.89(1.23)$ & $1.95(1.33)$ & $2.02(1.36)$ & 0.004 \\
\hline Total cholesterol (mmol/l) & $5.82(1.01)$ & $5.88(1.09)$ & $5.87(1.05)$ & 0.480 \\
\hline HDL-cholesterol (mmol/l) & $1.61(0.42)$ & $1.59(0.39)$ & $1.56(0.39)$ & 0.002 \\
\hline Cholesterol ratio $^{\mathrm{d}}$ & $3.85(1.14)$ & $3.92(1.20)$ & $3.99(1.18)$ & 0.002 \\
\hline Fibrinogen $(\mu \mathrm{mol} / \mathrm{l})$ & $8.35(1.71)$ & $8.47(1.68)$ & $8.76(1.79)$ & $<0.001$ \\
\hline CRP (mg/l) & $1.83(4.05)$ & $2.06(5.82)$ & $2.17(3.93)$ & $<0.001$ \\
\hline Waist $(\mathrm{cm})$ & $89.8(12.7)$ & $90.9(13.4)$ & $92.0(13.3)$ & $<0.001$ \\
\hline BMI $\left(\mathrm{kg} / \mathrm{m}^{2}\right)$ & $26.5(4.50)$ & $26.8(4.67)$ & $27.5(4.85)$ & $<0.001$ \\
\hline Systolic blood pressure $(\mathrm{mmHg})$ & $124(15.5)$ & $126(16.2)$ & $126(16.3)$ & 0.017 \\
\hline Diastolic blood pressure $(\mathrm{mmHg})$ & $77.3(10.7)$ & $78.0(10.7)$ & $78.3(10.7)$ & 0.017 \\
\hline Clustered cardiometabolic risk & $-0.13(0.62)$ & $-0.07(0.60)$ & $-0.01(0.61)$ & $<0.001$ \\
\hline
\end{tabular}

cholesterol: total cholesterol ratios. There was a high degree of consistency in TV viewing behaviours over adulthood. Thus in a multivariate analysis (adjusted for sex, social class and recreational physical activity), participants who reported TV viewing $\geq 5$ times/week at age 23 years had a greater than two and a half times higher odds of reporting $\geq 2 \mathrm{~h} /$ day of $\mathrm{TV}$ viewing at age 44 years compared with those reporting twice a week or less (ESM Table 2).

Table 2 presents the associations between TV viewing frequency at age 23 years and both cardiometabolic risk markers and clustered cardiometabolic risk score at age 44 years. All examined risk markers and the clustered cardiometabolic risk score showed sex-adjusted associations with TV viewing frequency at age 23 years. Once analyses were adjusted for potential confounders, and for TV viewing and physical activity at age 44 years, these associations persisted for CRP, fibrinogen, waist circumference, systolic and diastolic blood pressure, and clustered cardiometabolic risk score; associations were attenuated to the null for all other outcomes $\left(\mathrm{HbA}_{1 \mathrm{c}}\right.$, triacylglycerol and cholesterol ratio).

Although we found a significant sex $\times$ TV viewing interaction in terms of the cholesterol ratio $(p=0.027)$, sex-stratified analyses showed no appreciably different results (data not shown). We also found a sex interaction in terms of the clustered cardiometabolic risk score $(p=$ 0.035). As Table 3 shows, the association between TV viewing at age 23 years and clustered cardiometabolic risk score was more pronounced in men than in women.

The prevalence of overweight $\left(B M I \geq 25 \mathrm{~kg} / \mathrm{m}^{2}\right)$ at age 23 years was $14.5 \%$ (16.9\% for men, $12.2 \%$ for women). The corresponding figure for obesity prevalence $\left(\mathrm{BMI} \geq 30 \mathrm{~kg} / \mathrm{m}^{2}\right)$ was $2.0 \%$ (1.8\% and $2.1 \%$ for men and women, respectively). When we additionally adjusted the multivariable models for baseline BMI, the previously observed associations between TV viewing and fibrinogen (Fig. 1a), CRP (Fig. 1b), waist circumference (Fig. 1c), systolic (Fig. 1d) and diastolic (Fig. 1e) blood pressure, and clustered cardiometabolic risk score (Fig. 1f) were all attenuated. We further explored the role of baseline BMI by stratifying our analyses by overweight status. Most of the multivariable-adjusted associations observed in Table 2 persisted for participants with a $\mathrm{BMI}<25 \mathrm{~kg} / \mathrm{m}^{2}$ at age 23 years $(n=5,039)$, but were attenuated to null for those with a BMI $\geq 25 \mathrm{~kg} / \mathrm{m}^{2}$ $(n=857)($ ESM Table 3$)$. 
Table 2 Multivariable-adjusted associations between TV frequency at age 23 years and cardiometabolic risk at age 44 years: the BBC58 $(n=5972)$

\begin{tabular}{|c|c|c|c|}
\hline $\begin{array}{l}\text { TV frequency (times/week) } \\
\text { per variable }\end{array}$ & $\begin{array}{l}\text { Model } 1^{\mathrm{a}} \\
\text { Coefficient } \mathrm{t}^{\mathrm{b}} \text { or percentage } \\
\text { change }^{\mathrm{c}}(95 \% \mathrm{CI})\end{array}$ & $\begin{array}{l}\text { Model } 2^{\mathrm{a}} \\
\text { Coefficient }{ }^{\mathrm{b}} \text { or percentage } \\
\text { change }^{\mathrm{c}}(95 \% \mathrm{CI})\end{array}$ & $\begin{array}{l}\text { Model } 3^{\mathrm{a}} \\
\text { Coefficient }^{\mathrm{b}} \text { or percentage } \\
\text { change }^{\mathrm{c}}(95 \% \mathrm{CI})\end{array}$ \\
\hline \multicolumn{4}{|l|}{$\mathrm{HbA}_{1 \mathrm{c}}(\%)^{\mathrm{b}}$} \\
\hline$\leq 2$ & Referent & Referent & Referent \\
\hline $3-4$ & $0.006(-0.052,0.065)$ & $-0.001(-0.084,0.081)$ & $-0.003(-0.061,0.054)$ \\
\hline$\geq 5$ & $0.065(0.018,0.112)$ & $0.034(-0.033,0.101)$ & $0.018(-0.030,0.066)$ \\
\hline \multicolumn{4}{|l|}{$\mathrm{HbA}_{1 \mathrm{c}}(\mathrm{mmol} / \mathrm{mol})^{\mathrm{b}}$} \\
\hline$\leq 2$ & Referent & Referent & Referent \\
\hline $3-4$ & $0.069(-0.569,0.708)$ & $-0.010(-0.638,0.618)$ & $-0.038(-0.668,0.592)$ \\
\hline$\geq 5$ & $0.710(0.195,1.225)$ & $0.261(-0.251,0.773)$ & $0.192(-0.333,0.716)$ \\
\hline Trend $p$ value & 0.002 & 0.242 & 0.422 \\
\hline \multicolumn{4}{|l|}{ Triacylglycerol $(\mathrm{mmol} / \mathrm{l})^{\mathrm{c}}$} \\
\hline$\leq 2$ & Referent & Referent & Referent \\
\hline $3-4$ & $1.9(-3.0,6.9)$ & $1.5(-3.2,6.5)$ & $0.2(-4.5,5.0)$ \\
\hline$\geq 5$ & $7.9(3.9,12.2)$ & $5.4(1.4,9.6)$ & $1.9(-2.1,6.1)$ \\
\hline Trend $p$ value & $<0.001$ & 0.005 & 0.357 \\
\hline \multicolumn{4}{|l|}{ Cholesterol ratio $(\mathrm{mmol} / 1)^{\mathrm{b}, \mathrm{d}}$} \\
\hline$\leq 2$ & Referent & Referent & Referent \\
\hline $3-4$ & $0.065(-0.031,0.161)$ & $0.051(-0.042,0.144)$ & $0.022(-0.070,0.114)$ \\
\hline$\geq 5$ & $0.172(0.094,0.250)$ & $0.090(0.014,0.165)$ & $0.016(-0.061,0.093)$ \\
\hline Trend $p$ value & $<0.001$ & 0.020 & 0.785 \\
\hline \multicolumn{4}{|l|}{ Fibrinogen $(\mu \mathrm{mol} / \mathrm{l})^{\mathrm{c}}$} \\
\hline$\leq 2$ & Referent & Referent & Referent \\
\hline $3-4$ & $1.8(0.1,3.7)$ & $1.5(-0.2,3.4)$ & $1.1(-0.6,2.8)$ \\
\hline$\geq 5$ & $4.7(3.1,6.2)$ & $2.8(1.4,4.3)$ & $1.8(0.3,3.3)$ \\
\hline Trend $p$ value & $<0.001$ & $<0.001$ & 0.020 \\
\hline \multicolumn{4}{|l|}{$\mathrm{CRP}(\mathrm{mg} / \mathrm{l})^{\mathrm{c}}$} \\
\hline$\leq 2$ & Referent & Referent & Referent \\
\hline $3-4$ & $11.9(0.7,24.2)$ & $10.6(-0.3,22.6)$ & $6.5(-3.9,18.2)$ \\
\hline$\geq 5$ & $32.8(22.1,44.6)$ & $24.0(13.9,35.0)$ & $12.6(3.5,22.8)$ \\
\hline Trend $p$ value & $<0.001$ & $<0.001$ & 0.005 \\
\hline \multicolumn{4}{|l|}{ Waist circumference $(\mathrm{cm})^{\mathrm{b}}$} \\
\hline$\leq 2$ & Referent & Referent & Referent \\
\hline $3-4$ & $0.840(-0.184,1.863)$ & $0.758(-0.260,1.775)$ & $0.351(-0.659,1.361)$ \\
\hline$\geq 5$ & $2.598(1.772,3.424)$ & $2.196(1.366,3.025)$ & $1.166(0.325,2.008)$ \\
\hline Trend $p$ value & $<0.001$ & $<0.001$ & 0.004 \\
\hline \multicolumn{4}{|l|}{ Systolic BP $(\mathrm{mmHg})^{\mathrm{b}}$} \\
\hline$\leq 2$ & Referent & Referent & Referent \\
\hline $3-4$ & $1.391(0.059,2.722)$ & $1.379(0.050,2.708)$ & $1.110(-0.220,2.440)$ \\
\hline$\geq 5$ & $2.203(1.129,3.278)$ & $2.105(1.022,3.189)$ & $1.438(0.330,2.546)$ \\
\hline Trend $p$ value & $<0.001$ & $<0.001$ & 0.019 \\
\hline \multicolumn{4}{|l|}{ Diastolic BP $(\mathrm{mmHg})^{\mathrm{b}}$} \\
\hline$\leq 2$ & Referent & Referent & Referent \\
\hline $3-4$ & $0.614(-0.296,1.524)$ & $0.622(-0.286,1.529)$ & $0.415(-0.492,1.323)$ \\
\hline$\geq 5$ & $1.235(0.501,1.969)$ & $1.268(0.528,2.008)$ & $0.752(-0.005,1.508)$ \\
\hline Trend $p$ value & 0.001 & 0.001 & 0.053 \\
\hline \multicolumn{4}{|c|}{ Clustered cardiometabolic risk $(\mathrm{SD})^{\mathrm{b}}$} \\
\hline$\leq 2$ & Referent & Referent & Referent \\
\hline
\end{tabular}


Table 2 (continued)

\begin{tabular}{|c|c|c|c|}
\hline $\begin{array}{l}\text { TV frequency (times/week) } \\
\text { per variable }\end{array}$ & $\begin{array}{l}\text { Model } 1^{\mathrm{a}} \\
\text { Coefficient }^{\mathrm{b}} \text { or percentage } \\
\text { change }^{\mathrm{c}}(95 \% \mathrm{CI})\end{array}$ & $\begin{array}{l}\text { Model } 2^{\mathrm{a}} \\
\text { Coefficient }^{\mathrm{b}} \text { or percentage } \\
\text { change }^{\mathrm{c}}(95 \% \mathrm{CI})\end{array}$ & $\begin{array}{l}\text { Model } 3^{\mathrm{a}} \\
\text { Coefficient }^{\mathrm{b}} \text { or percentage } \\
\text { change }^{\mathrm{c}}(95 \% \mathrm{CI})\end{array}$ \\
\hline $3-4$ & $0.057(0.007,0.107)$ & $0.048(0.000,0.096)$ & $0.027(-0.021,0.074)$ \\
\hline$\geq 5$ & $0.162(0.122,0.202)$ & $0.110(0.071,0.149)$ & $0.055(0.016,0.095)$ \\
\hline Trend $p$ value & $<0.001$ & $<0.001$ & 0.006 \\
\hline
\end{tabular}

${ }^{\text {a }}$ Model 1: adjusted for sex; model 2: further adjustments for smoking, social class, drinking and cardiovascular medication (all measured at age 44 years); model 3: further adjustments for physical activity at age 23 and 44 years, and TV viewing at age 44 years

${ }^{\mathrm{b}}$ Generalised linear model coefficients; coefficients indicate mean differences (in risk factor values) between the reference category $(\leq 2$ times a week) and each of the other TV viewing groups at age 23 years, e.g. a value of 1.5 indicates that a specific category had a mean score that is 1.5 units higher than the referent group

${ }^{\mathrm{c}}$ Percentage change was used for variables that were log-transformed (using the natural log) before being entered into the generalised linear model tests (triacylglycerol, fibrinogen and CRP); the percentage change was calculated by back-transforming the logged coefficients to their natural scale through exponentiation, and then subtracting 1 and multiplying by 100

${ }^{\mathrm{d}}$ Calculated as total cholesterol: HDL-cholesterol

\section{Discussion}

Our study found associations between frequency of TV viewing in early adulthood and adverse cardiometabolic profiles in early middle age. These associations were driven by haemostatic (fibrinogen), inflammatory (CRP), haemodynamic (systolic and diastolic blood pressure) and adiposity-related (waist circumference) outcomes. Our results expand on several cross-sectional studies that have looked at the association between sedentary behaviour and clustered cardiometabolic risk factors [5] or the metabolic syndrome $[11,12]$, and have consistently reported associ-

Table 3 Sex-stratified and multivariable-adjusted ${ }^{\mathrm{a}}$ associations between TV frequency at age 23 years and clustered cardiometabolic risk at age 44 years: the $\operatorname{BBC} 58(n=5629)$

\begin{tabular}{lll}
\hline $\begin{array}{l}\text { TV frequency } \\
\text { (times/week) }\end{array}$ & \begin{tabular}{l} 
Clustered risk \\
\cline { 2 - 3 }
\end{tabular} & $\begin{array}{l}\text { Men }(\text { coefficient } \\
\left.[95 \% \mathrm{CI}]^{\mathrm{b}}\right)\end{array}$ \\
\hline$n$ & $\begin{array}{l}\text { Women }(\text { coefficient } \\
\left.[95 \% \mathrm{CI}]^{\mathrm{b}}\right)\end{array}$ \\
$\leq 2$ & Referent & 3,025 \\
$3-4$ & $0.045(-0.018,0.108)$ & Referent \\
$\geq 5$ & $0.057(0.005,0.110)$ & $0.008(-0.063,0.080)$ \\
Trend $p$ value & 0.038 & 0.071
\end{tabular}

\footnotetext{
${ }^{a}$ Adjustments for smoking, social class, drinking, cardiovascular medication (all measured at age 44), physical activity at 23 and 44 years, and TV viewing at age 44 years

${ }^{\mathrm{b}}$ Coefficients indicate mean clustered cardiometabolic risk score differences between the reference category and each other TV group at age 23 years, e.g. a positive value of 1.5 indicates that a specific category had a mean component score that is 1.5 units higher than the referent group
}

ations that are independent of MVPA. For example, Healy and colleagues [5] found that objectively measured total sedentary time was independently associated with a metabolic risk score (comprising waist circumference, triacylglycerol, blood pressure, HDL-cholesterol and fasting plasma glucose) among 169 middle-aged Australians. The clustered cardiometabolic risk score we developed is roughly equivalent to this cluster of risk factors (minus plasma glucose), as well as to the constituent components of the International Diabetes Federation definition of the metabolic syndrome [39]. All other aforementioned studies that used metabolic syndrome as an outcome are also comparable with our results, as all popular metabolic syndrome definitions include obesity (BMI or waist circumference), triacylglycerol, blood pressure and HDL-cholesterol [40]. It is therefore encouraging that our results expand on the existing crosssectional evidence. Although some cross-sectional studies using objective measures of sedentary behaviour found deleterious associations with plasma glucose $[4,5]$, other studies that used objective [6] or self-reported measures [13] noted no association. We, in other recent work, failed to find any associations between objectively assessed total sedentary behaviour or self-reported TV viewing time and $\mathrm{HbA}_{1 \mathrm{c}}$ in adults of working age (E. Stamatakis, M. Hamer, K. Tilling and D.A. Lawlor, unpublished results) and older adults (E. Stamatakis, M. Davis, A. Stathi and M. Hamer, unpublished results). To our knowledge, the only longitudinal study that is comparable to ours [13] found associations between increase in TV viewing over time and adverse changes in clustered cardiometabolic risk and in certain individual risk markers (waist and diastolic, but not systolic blood pressure), although baseline TV viewing was not associated with any of these outcomes 

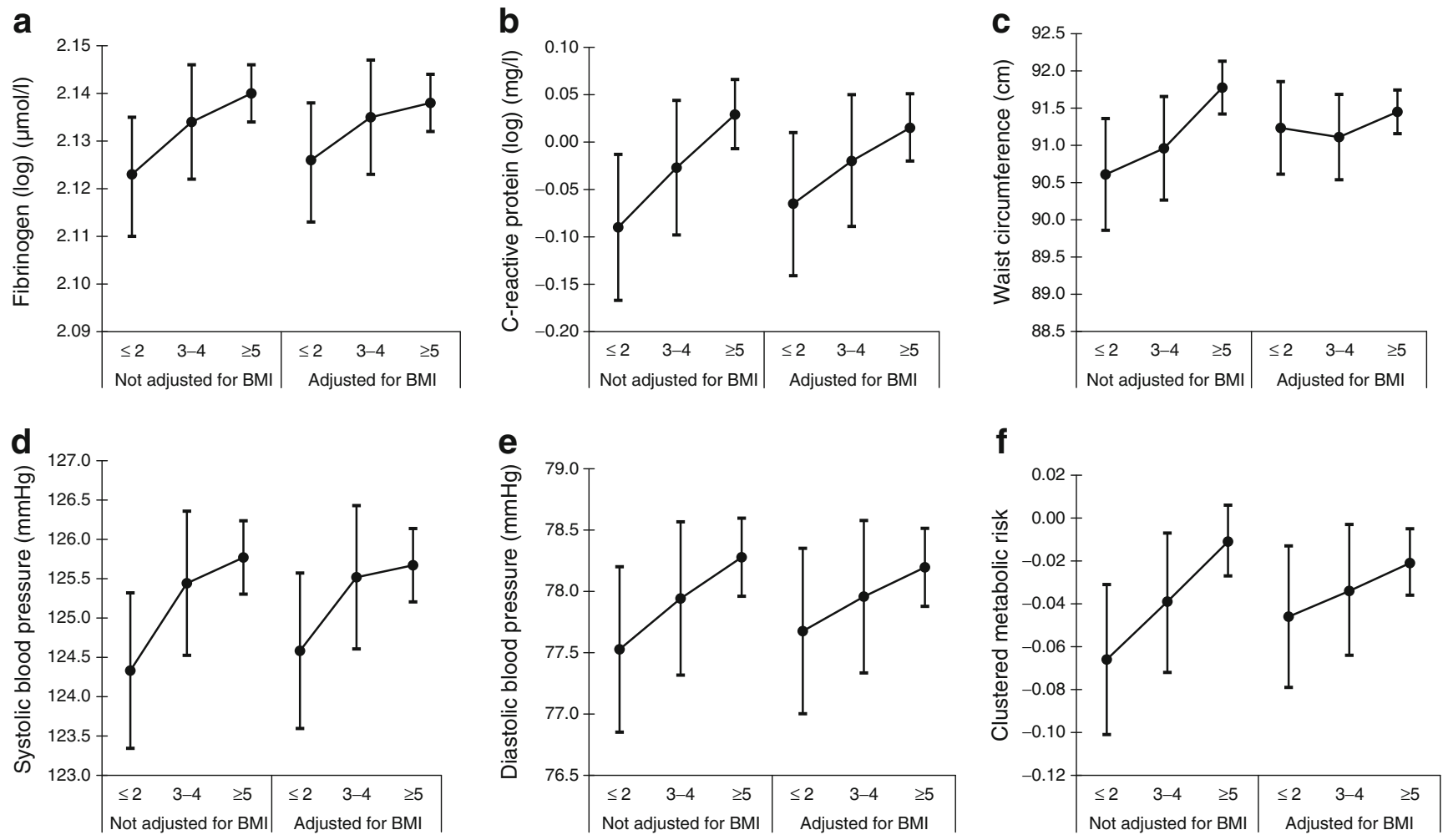

Fig. 1 Multivariable-adjusted means and 95\% CIs of cardiometabolic risk markers and clustered cardiometabolic risk score by TV viewing frequency $(\leq 2,3-4, \geq 5$ times per week) at age 23 years with and without adjustments for baseline BMI (at age 23 years). a Fibrinogen ( $\log$ ), not adjusted for BMI $p=0.020$, adjusted for BMI $p=0.088$; $\mathbf{b}$ CRP ( $\log$ ), not adjusted for BMI $p=0.005$, adjusted for BMI $p=0.050$. c Waist circumference, not adjusted for BMI $p=0.004$, adjusted for BMI

or with raised triacylglycerol, HDL-cholesterol and glucose.

If the associations we identified are causal, increased TV viewing may increase the risk of CVD and all-cause mortality, as we [8] and others [21] have shown. We did not find associations between TV viewing and lipid-related risk markers (triacylglycerol and cholesterol ratio), a finding that is partly explained by another current study of ours, where we examined to what extent certain metabolic (BMI, HDL-cholesterol, total cholesterol) and inflammatory (CRP) risk factors explain the association between screen-based entertainment time (comprising mainly TV viewing) and clinically confirmed fatal/nonfatal CVD events. In that other study, these four biological factors explained $28 \%$ of the association between screen-based entertainment and CVD [8]. CRP explained CVD events to the greatest extent ( $20 \%)$, with HDL-cholesterol explaining approximately $8 \%$ and total cholesterol explaining only $1.6 \%$ [8]. To assess the possibility that the lack of the association between our exposure and the cholesterol ratio in the current study was not driven by total cholesterol, we repeated the analyses $p=0.384$. d Systolic blood pressure, not adjusted for BMI $p=0.019$, adjusted for BMI $p=0.072$. e Diastolic blood pressure, not adjusted for BMI $p=0.053$, adjusted for BMI $p=0.159$. f Clustered cardiometabolic risk, not adjusted for BMI $p=0.006$, adjusted for BMI $p=0.148$. All models were adjusted for sex, smoking, social class, drinking and cardiovascular medication (all measured at age 44 years), physical activity at 23 and 44 years, and TV viewing at age 44 years

with cholesterol and HDL-cholesterol entered as two separate outcomes, but the null findings persisted (data not shown). Therefore, our results offer little support to the hypothesis derived from animal models that prolonged sedentary behaviour may disturb lipid metabolism [26], although it remains possible that TV viewing in general $[16,41]$ or TV viewing frequency in particular is merely a poor indicator of sitting.

We found that the higher the TV viewing frequency at age 23 years, the higher the odds of reporting increased TV viewing times at age 44 years (ESM Table 2). This tendency may lead to the development of adverse cardiometabolic risk profiles by the mid $40 \mathrm{~s}$ and it is logical to assume that, unless lifestyle changes occur, these profiles will deteriorate later in life due to degenerative processes. The induction of 5 days bed rest, which represents an extreme form of sedentary behaviour, has profound effects on various metabolic risk factors, including microvascular dysfunction, although it does not significantly impact on inflammatory markers [42]. Thus, low-grade inflammation might only result from chronic exposure to a sedentary lifestyle. It is also possible that sitting-induced microvas- 
cular dysfunction is linked with impaired haemostasis, explaining the associations we found between TV viewing and fibrinogen.

Nevertheless, we acknowledge that the influence of TV viewing on cardiometabolic risk may not be causal, e.g. if TV viewing acts through other behavioural risk factors that we were unable to measure, such as consuming high-energy snack foods and/or the influence of TV advertisements on eating behaviours [43]. Beside behavioural residual confounding, we [44] and others [45] have reported TV viewing to be associated with adverse psychological outcomes. Given that cardiometabolic risk is associated with psychological factors [46, 47], this may be another potential pathway through which TV viewing adversely affects cardiometabolic risk profile.

The associations observed by us between TV viewing and cardiometabolic risk were independent of physical activity at both time points and of TV viewing at age 44 years, but not of baseline BMI at age 23 years. Although adjustments for BMI in another of our studies [8] did not considerably attenuate the associations between screenbased entertainment and CVD events, results from a different study of ours [48] are consistent with the present study. In that study, we examined the extent to which BMI and waist circumference explained the associations between multi-domain sedentary behaviour (TV viewing, other leisure-time sitting, occupational sitting) and established cardiometabolic risk factors (total cholesterol, HDLcholesterol, systolic and diastolic blood pressure) among 5,067 English adults from the general population [48]. Adjustments for BMI or waist circumference attenuated the associations between total sedentary behaviour or TV viewing alone and the above risk markers towards null. BMI explained between $33 \%$ and $96 \%$ of the associations of the risk markers with total sedentary behaviour and between $29 \%$ and $60 \%$ of the associations with TV viewing alone [48]. Although, due to the cross-sectional design of the above study, these findings cannot clarify whether BMI is a confounder or a mediator, they do lend support to the idea that the relationship between sedentary behaviour and adiposity may be bi-directional, as suggested before [10]. A previous study on the same cohort (BBC58) found that TV viewing at age 23 years predicted BMI (women only) and waist circumference at age 44 years [31]. Our findings here expand on this by showing that TV viewing at age 23 years is linked not only to adiposity, but also to more comprehensive risk factor profiles.

The main strengths of our study are the long ( $>20$ years) follow-up period and the broad range of risk factors that allowed us to examine comprehensive profiles of cardiometabolic risk. On the other hand, our main exposure (TV viewing at age 23 years) was measured in a crude way and therefore our study is inappropriate for examining dose- response relationships. Nevertheless, we would expect that with a more accurate exposure measurement, the associations observed by us would have been stronger and, perhaps, robust to BMI adjustments. Furthermore, there is no information on the reliability and criterion validity of the questions assessing TV viewing at age 2 years. In this light, it is encouraging that a recent review [16] concluded that sedentary time questions focusing on TV viewing have the strongest reliability and validity among non-occupational sedentary behaviour questions. Although TV viewing is not a complete indicator of sedentary behaviour, it may be argued that it is perhaps the most important: the 2005 UK Time Use survey indicates that, aside from sleeping, watching TV is the behaviour that occupies the most time in the domestic setting [17]. With the exception of BMI, data on all other biological risk markers were not available at the baseline assessment (23 years), so we cannot entirely rule out the possibility of reverse causality. Nevertheless, the prevalence of overweight and obesity was low at age 23 years, and it is highly unlikely that high levels of inflammatory and haemostatic risk factors were present in young adulthood. The blood samples were nonfasting, but for the assays used $\left(\mathrm{HbA}_{1 \mathrm{c}}\right.$, HDLcholesterol, total cholesterol) this would not be expected to have biased results [49]. Finally, the relatively large proportion of participants $(36 \%)$ excluded from analyses due to missing data might have introduced bias into our results. Comparisons between the excluded and included groups of the sample revealed that those excluded had an adverse health behaviour profile at follow-up, as they were more likely to smoke, watch high amounts of TV, be physically inactive, and to rarely or never drink alcohol (which may be seen as an adverse health behaviour due to the J-shaped association between alcohol drinking and cardiovascular health). They were also more likely to be male and from a manual work social class (both of which are known cardiometabolic risk factor), and to be on CVD medication. If the excluded part of the sample had more adverse cardiometabolic risk factor profiles, the associations we observed may have been underestimated due to reduced variability in the outcome variables. However, we cannot meaningfully test this assumption because most missing values were in the biochemical outcome variables.

Conclusion Frequency of TV viewing in early adulthood is associated with fibrinogen, CRP, blood pressure and clustered cardiometabolic risk (in men only) in early middle age. These associations are independent of physical activity, but dependent on baseline BMI. Future cohort studies with detailed measures of TV viewing and sedentary behaviour are needed to confirm these results in other diverse populations, to establish specific thresholds of daily TV 
viewing and to further investigate the links between sedentary behaviour and obesity.

Acknowledgements We would like to thank N. Coombs (Department of Epidemiology and Public Health, University College London) for her assistance with preparing and submitting the revised manuscript. This report is independent research arising from a Career Development Fellowship (to E. Stamatakis) supported by the National Institute for Health Research. The views expressed in this publication are those of the author(s) and not necessarily those of the NHS, the National Institute for Health Research or the Department of Health. M. Hamer is funded by the British Heart Foundation and G. D. Mishra was being funded by the Medical Research Council when this study was conducted. The 1958 British Birth Cohort data collections used in these analyses were funded by several sources (1981: Department of Health and Social Security, Department of Education and Science, Department of Employment, Manpower Services Commission, Department of the Environment; 2002 and 2003: Medical Research Council, Wellcome Trust).

Contribution statement ES conceived and developed the idea, designed and carried out the statistical analysis, and drafted and revised the manuscript. $\mathrm{MH}$ contributed to the idea development and interpretation of the results, and critically reviewed and approved the manuscript. GM contributed to the statistical design, analysis and interpretation of the results, and critically reviewed and approved the manuscript. All authors approved the final version of the manuscript.

Duality of interest The authors declare that there is no duality of interest associated with this manuscript.

\section{References}

1. Warburton DE, Nicol CW, Bredin SD (2006) Health benefits of physical activity: the evidence. Can Med Assoc J 174:801-809

2. Stamatakis E, Hirani V, Rennie K (2009) Moderate-to-vigorous physical activity and sedentary behaviours in relation to body mass index-defined and waist circumference-defined obesity. Br J Nutr 101:765-773

3. Jakes RW, Day NE, Khaw KT et al (2003) Television viewing and low participation in vigorous recreation are independently associated with obesity and markers of cardiovascular disease risk: EPIC-Norfolk population-based study. Eur J Clin Nutr 57:1089-1096

4. Healy GN, Dunstan DW, Salmon J et al (2007) Objectively measured light-intensity physical activity is independently associated with 2-h plasma glucose. Diabetes Care 30:1384-1389

5. Healy GN, Wijndaele K, Dunstan DW et al (2008) Objectively measured sedentary time, physical activity, and metabolic risk: the Australian Diabetes, Obesity and Lifestyle Study (AusDiab). Diabetes Care 31:369-371

6. Healy GN, Matthews CE, Dunstan DW, Winkler EAH, Owen N (2011) Sedentary time and cardio-metabolic biomarkers in US adults: NHANES 2003-06. Eur Heart J 32:590-597

7. Katzmarzyk P, Church T, Craig C, Bouchard C (2009) Sitting time and mortality from all causes, cardiovascular disease, and cancer. Med Sci Sports Exe 41:998-1005

8. Stamatakis E, Hamer M, Dunstan DW (2011) Television and other screen-based entertainment time and cardiovascular events: population-based study with ongoing mortality and hospital events follow up. J Am Col Cardiol 57:292-299

9. Dunstan DW, Barr ELM, Healy GN et al (2010) Television viewing time and mortality: the Australian Diabetes, Obesity and Lifestyle Study (AusDiab). Circulation 121:384-391

10. Ekelund U, Brage S, Besson H, Sharp S, Wareham NJ (2008) Time spent being sedentary and weight gain in healthy adults: reverse or bidirectional causality? Am J Clin Nutr 88:612-617

11. Gao X, Nelson ME, Tucker KL (2007) Television viewing is associated with prevalence of metabolic syndrome in Hispanic elders. Diabetes Care 30:694-700

12. Dunstan DW, Salmon J, Owen N, Armstrong T, Zimmet PZ (2005) Associations of TV viewing and physical activity with the metabolic syndrome in Australian adults. Diabetologia 48:2254-2261

13. Wijndaele K, Healy GN, Dunstan DW et al (2010) Increased cardiometabolic risk is associated with increased TV viewing time. Med Sci Sports Exe 42:1511-1518

14. Kabrhel C, Varraso R, Goldhaber SZ, Rimm E, Camargo CA (2011) Physical inactivity and idiopathic pulmonary embolism in women: prospective cohort study. BMJ 343:d3867

15. Esmon CT (2009) Basic mechanisms and pathogenesis of venous thrombosis. Blood Rev 23:225-229

16. Clark BK, Sugiyama T, Healy GN, Salmon J, Dunstan DW, Owen $\mathrm{N}$ (2009) Validity and reliability of measures of television viewing time and other non-occupational sedentary behaviour of adults: a review. Obes Rev 10:7-16

17. Office for National Statistics (2006) The UK time use survey 2005. The Stationery Office, London

18. Australian Bureau of Statistics (2006) How Australians use their time, 2006. Australian Bureau of Statistics, Canberra

19. United States Department of Labor (2008) American Time Use Survey-2007 Results. United States Department of Labor, Washington, DC

20. Joint Health Surveys Unit (2009) The Health Survey for England 2008. The Health and Social Care Information Centre, Leeds

21. Grøntved A, Hu FB (2011) Television viewing and risk of type 2 diabetes, cardiovascular disease and all-cause mortality. JAMA 203:2448-2455

22. O'Donovan G, Blazevich AJ, Boreham C et al (2010) The ABC of physical activity for health: a consensus statement from the British Association of Sport and Exercise Sciences. J Sports Sci 28:573-591

23. Haskell WL, Lee IM, Pate RR (2007) Physical activity and public health: updated recommendation for adults from the American College of Sports Medicine and the American Heart Association. Med Sci Sports Exe 39:1423-1434

24. Department of Health and Human Services (2008) 2008 Physical activity guidelines for Americans. Department of Health and Human Services, Washington, DC

25. Stamatakis E, Chaudhury M (2008) Temporal trends in adults' sports participation patterns in England between 1997 and 2006: the Health Survey for England. Br J Sports Med 42:601-608

26. Hamilton MT, Hamilton DG, Zderic TW (2007) Role of low energy expenditure and sitting in obesity, metabolic syndrome, type 2 diabetes, and cardiovascular disease. Diabetes 56:2655-2667

27. Allender S, Cowburn G, Foster C (2006) Understanding participation in sport and physical activity among children and adults: a review of qualitative studies. Health Educ Res 21:826-835

28. Power C, Elliott J (2006) Cohort profile: 1958 British Birth Cohort (National Child Development Study). Int J Epidemiol $35: 34-41$

29. Tabassum F, Kumari M, Rumley A, Lowe G, Power C, Strachan DP (2008) Effects of socioeconomic position on inflammatory and 
hemostatic markers: a life-course analysis in the 1958 British Birth Cohort. Am J Epidemiol 167:1332-1341

30. Czernichow S, Kengne AP, Stamatakis E, Hamer M, Batty GD (2011) Body mass index, waist circumference and waist-hip ratio: which is the better discriminator of cardiovascular disease mortality risk? Evidence from an individual-participant metaanalysis of 82,864 participants from nine cohort studies. Obes Rev 12:680-687

31. Parsons TJ, Manor O, Power C (2007) Television viewing and obesity: a prospective study in the 1958 British Birth Cohort. Eur J Clin Nutr 62:1355-1363

32. Parsons TJ, Thomas C, Power C (2009) Estimated activity patterns in British 45 year olds: cross-sectional findings from the 1958 British Birth Cohort. Eur J Clin Nutr 63:978-985

33. Wareham NJ, Jakes RW, Rennie KL, Mitchell J, Hennings S, Day NE (2002) Validity and repeatability of the EPIC-Norfolk Physical Activity Questionnaire. Int J Epidemiol 31:168-174

34. Ainsworth BE, Haskell WL, Whitt MC (2000) Compendium of physical activities: an update of activity codes and MET intensities. Med Sci Sports Exe 32:S498-S516

35. Stamatakis E, Ekelund U, Wareham NJ (2007) Temporal trends in physical activity in England: the Health Survey for England 1991 to 2004. Prev Med 45:416-423

36. Szreter SRS (1984) The genesis of the registrar-general's social classification of occupations. Br J Sociol 35:522-546

37. Prospective Studies Collaboration (2007) Blood cholesterol and vascular mortality by age, sex, and blood pressure: a metaanalysis of individual data from 61 prospective studies with 55,000 vascular deaths. Lancet 370:1829-1839

38. Ekelund U, Griffin SJ, Wareham NJ (2007) Physical activity and metabolic risk in individuals with a family history of type 2 diabetes. Diabetes Care 30:337-342

39. International Diabetes Federation (2006) The IDF consensus worldwide definition of the metabolic syndrome. International Diabetes Federation, Brussels. Available from www.idf.org/webdata/docs/ IDF Meta def final.pdf. Accessed 7 October 2011

40. Grundy SM, Brewer HB Jr, Cleeman JI, Smith SC Jr, Lenfant C (2004) Definition of metabolic syndrome: report of the National
Heart, Lung, and Blood Institute/American Heart Association Conference on Scientific Issues Related to Definition. Circulation 109:433-438

41. Sugiyama T, Healy G, Dunstan DW, Salmon J, Owen N (2008) Is television viewing time a marker of a broader pattern of sedentary behavior? Ann Behav Med 35:245-250

42. Hamburg NM, McMackin CJ, Huang AL et al (2007) Physical inactivity rapidly induces insulin resistance and microvascular dysfunction in healthy volunteers. Art Thromb Vasc Biol 27:2650-2656

43. Cleland VJ, Schmidt MD, Dwyer T, Venn AJ (2008) Television viewing and abdominal obesity in young adults: is the association mediated by food and beverage consumption during viewing time or reduced leisure-time physical activity? Am J Clin Nutr $87: 1148-1155$

44. Hamer M, Stamatakis E, Mishra GD (2010) Television- and screen-based activity and mental well-being in adults. Am J Prev Med 38:375-380

45. Primack BA, Swanier B, Georgiopoulos AM, Land SR, Fine MJ (2009) Association between media use in adolescence and depression in young adulthood a longitudinal study. Arch Gen Psychiatry 66:181-188

46. Vogelzangs N, Beekman ATF, Kritchevsky SB et al (2007) Psychosocial risk factors and the metabolic syndrome in elderly persons: findings from the Health, Aging and Body Composition Study. J Gerontol A Biol Sci Med Sci 62:563-569

47. Räikkönen K, Matthews KA, Kuller LH (2002) The relationship between psychological risk attributes and the metabolic syndrome in healthy women: antecedent or consequence? Metabolism 51:1573-1577

48. Stamatakis E, Hamer M (2011) The extent to which adiposity markers explain the association between sedentary behaviour and cardiometabolic risk factors. Obesity. doi:10.1038/ oby. 2011.209

49. Mora S, Rifai N, Buring JE, Ridker PM (2008) Fasting compared with non fasting lipids and 506 apolipoproteins for predicting incident cardiovascular events. Circulation 118:9931001 